\title{
Editorial for Journal of Medical Oncology and Therapeutics
}

\author{
Obeagu Emmanuel Ifeanyi* \\ *Department of Haematology, Michael Okpara University of Agriculture Umudike, Nigeria.
}

Journal of Medical Oncology and Therapeutics is a transparent allied publisher with millions of website visitors and successfully releasing a second issue in the fifth volume with several interesting topic related articles and this achieved a great readership and honor from the voluntary associations of specialists conducting scientific research and persons with an interest in some branch of science other than their own field. Journal of Medical Oncology and Therapeutics is an open access magazine with the objective to publish Oncology and its medical and Therapeutic process related themes, as to better disclosure the knowledge about this matter. According to these oncology related studies we observe the views of the magazine on more over several high-income countries worldwide and with over 200 views in daily pages.

Where as discussing regarding the major highlights of this Journal of Medical Oncology and Therapeutics, it publishes online within the time and print issues were also brought out with the high-quality perfection in publishing the articles and dispatched within 30 days of publishing the issue online.

This Journal mainly encouraging the new scientific research studies to increase the scope of the journal and its quality for this purpose Journal would like to give some discounts in the article processing charges and guiding the authors in each and every process with polite nature from receiving to publishing.

Editorial board members are giving their best results in editing the assigned articles and journal appreciates their work for showing the quick responses and helping the article to process further. These editors add significant value to the research in the field of medical oncology and therapeutics. In same case reviewers are very active in reviewing the assigned article with great pleasure and the comments were very scientific and appreciable.

A statistical representation of global users for Journal of Medical Oncology and Therapeutics through a source named Google Analytics. It is a data that browser, viewers, and users are constantly visiting the web page of the journal from various quarters of the world $24 \times 7$. Approximately 6000 visitors have accessed the journal pages for reading and deriving information for their use. Majority of countries visiting journal website are from United States, United Kingdom, London, France, India, China etc. and other countries are also visiting for the best outcomes. Social media and digital marketing are also helpful in advertising for manuscript submission through Tweeter, LinkedIn, what's app and outlook mailing.

I would like to thank my gratitude to editors, authors, reviewers and other journal holders for their immense support in future growth for Journal of Medical Oncology and Therapeutics.

\section{Editorial Team}

Journal of Medical Oncology and Therapeutics *Obeagu Emmanuel Ifeanyi, Department of Haematology, Michael Okpara University of Agriculture Umudike, Nigeria E-mail: emmanuelobeagu@yahoo.com 